\title{
Development and Evaluation of Flurbiprofen Loaded Transethosomes to Improve Transdermal Delivery
}

\author{
Anand Panchaxari Gadad, Archana Sidagouda Patil*, Yashica Singh, Panchaxari Mallappa Dandagi, \\ Uday Baburao Bolmal, Ananya Basu
}

Department of Pharmaceutics, KLES College of Pharmacy, Constituent Unit of KLE Academy of Higher Education and Research, Belagavi, Karnataka, INDIA.

\begin{abstract}
Background: Flurbiprofen is prescribed for the symptomatic management of arthritis. Its oral administration leads to gastrointestinal damage and it has a short elimination halflife requiring multiple dosing. Transdermal drug delivery of flurbiprofen is an alternative route to bypass the stratum corneum layer of the skin. Nano-vesicular carriers can be used to overcome this problem as it increases the permeability and skin deposition of the drug and reduces dosing frequency. Materials and Methods: Flurbiprofen loaded Transethosomes has been formulated by Thin-film hydration using Span 80 and Tween 80 as edge activators, Soyaphosphotidylcholine and varying percentage of ethanol. The vesicles were further characterized to study the effect of the type and concentration of edge activator and ethanol percentage on various parameters such as, particles size, polydispersity index, deformability index, entrapment efficiency and in-vitro drug release. A formulation having the least particle size, highest deformability index and best ex-vivo profile was optimized. The optimized formulation was dispersed in a gelling agent and evaluated for $\mathrm{pH}$, drug content and compared with marketed formulation for ex-vivo permeation and skin deposition. Formulation containing Tween 80 in the ratio of 95:05 (Soyaphosphotidylcholine: Edge Activator) and having the highest ethanol percentage was optimized. Results and Discussion: On comparison with the marketed gel it was revealed that the optimized gel formulation containing higher concentration of Tween 80 had better ex-vivo profile and skin deposition. Conclusion: The formulated transethosomes may serve as potential carrier for effective management of arthritis.
\end{abstract}

Key words: Flurbiprofen, Transethosomes, Thin film hydration method, Edge activator, Soyaphosphotidylcholine.

\section{INTRODUCTION}

NSAID drugs like Flurbiprofen are prescribed for symptomatic management of arthritis owing to their higher efficacy and patient preference. Flurbiprofen is commercially available in the form of tablets, sustained release capsules, gels, ointments and creams. Oral administration of flurbiprofen for the treatment of arthritis leads to gastrointestinal damage due to inhibition of prostaglandin production and direct contact of the drug with the gastrointestinal mucosa. Further, the drug has short elimination half-life which requires multiple dosing. ${ }^{1,2}$ In the case of gels, drug levels after topical administration of NSAIDs are much lower than those achieved with oral administration of the same drug. ${ }^{3}$ This is because the intercellular lipid barrier in the stratum corneum layer of the skin acts as an impediment to the penetration of the drugs through the skin into the deeper layers. Transdermal drug delivery systems deliver the drugs through the skin into the deeper layers of the skin (cutaneous delivery) or into the bloodstream (percutaneous delivery) at a predetermined controlled rate with very little inter and intra patient variability. ${ }^{4}$ These systems allow continual introduction of drugs with short biological half- lives to the distant skin layers.
Submission Date: 17-03-2020; Revision Date: 08-06-2020; Accepted Date: 13-08-2020

DOI: 10.5530/ijper.54.4.189 Correspondence: Dr. Archana S. Patil Professor, Department of Pharmaceutics, KLE College of Pharmacy, KAHER, Nehru Nagar, Belagavi-590010, Karnataka, INDIA.

Phone: +919448309472

E-mail: archupharma@gmail. com

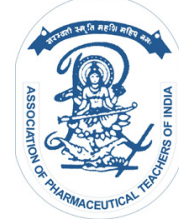

www.ijper.org 
However, many transdermal systems fail to pass through the rigid skin layers. These vesicles enhance transdermal delivery by integrating the benefits of both ethosomes and transferosomes for transdermal delivery of the drug through the skin as they contain both, an edge activator/ permeation enhancer and ethanol in their formula. Drug loaded nano vesicular systems and proved that transethosomes were superior to other vesicles due to improved stability and elasticity. ${ }^{5,6}$

In the present study, an attempt has been made to encapsulate Flurbiprofen in transethosomes to increase permeability, to reduce dose of the drug and to increase skin deposition. The optimized formulation was compared with the marketed formulation by conducting ex vivo permeation and in vitro skin deposition studies to establish which formulation has better permeability and deposition.

\section{MATERIALS AND METHODS}

\section{Materials}

Flurbiprofen was purchased from Yarrow Chem Pharmaceuticals Pvt. Ltd., Mumbai, India. Phosphotidylcholine-50 (Soyaphosphotidylcholine) was purchased from Lipidome Lifesciences, Ahmedabad, India. Tween 80 and Ethanol were obtained from S.D. Fine Chem Ltd., Mumbai, India. Span 80 and Carbopol 940 were purchased from HiMedia Laboratories Pvt. Ltd., Mumbai, India.

\section{Methods}

\section{Formulation of Flurbiprofen Loaded Transethosomal Suspension (FLU-TELS)}

Flurbiprofen was encapsulated in transethosomes by thin film hydration method described by Refai et al. using different ratios of Soyaphosphotidylcholine (SPC): edge activator (EA) and varying percentage of ethanol. ${ }^{7}$ Drug, SPC and EA were taken in a round bottom flask and dissolved in a 2:1 organic solvent mixture of chloroform: methanol. The organic solvent was evaporated under reduced pressure by rotating the flask at $60^{\circ} \mathrm{C}$ for 60 min at $90 \mathrm{rpm}$ using rotary evaporator until a thin film was formed on the edges of the flask. The film was allowed to dry overnight in a desiccator for $24 \mathrm{~h}$. Next day, the film was hydrated with Phosphate Buffer Saline (PBS of $\mathrm{pH}$ 7.4) and ethanol using rotary evaporator at room temperature. After this, the solution was kept at room temperature for $2 \mathrm{~h}$ for allowing the vesicles to swell. Further vesicle size reduction was carried out by sonicating the resulting vesicles by using probe sonicator. The formulations were refrigerated at $4^{\circ} \mathrm{C}$ till further analysis. The Flurbiprofen loaded transethosomal suspension (FLU-TELS) formulations with varying ratios of SPC, EA and varying concentration of ethanol, Tween 80 and Span 80 are shown in Table 1.

\section{Flurbiprofen Loaded Transethosomal Gel (FLU TELs Gel)}

In the preliminary studies, the gel base was prepared by soaking $0.5 \%, 1 \%$ and $2 \%$ of Carbopol 940 in PBS of $\mathrm{pH}$ overnight. Thereafter, $0.02 \%$ methyl and $0.01 \%$ propyl parabens were dissolved in 1\% propylene glycol and then incorporated in the gel base. Triethanolamine was added drop-wise for neutralization of the prepared gel base till $\mathrm{pH} 7.0$ reached. The optimized transethosomal formulation was dispersed in $0.5 \%, 1 \%$ and $2 \%$ of the gel base to obtain a total drug concentration of $0.5 \%$ w/w. On visual observation, the best consistency was observed with 2\% Carbopol 940 which was further used for the preparation of FLU-TELS gel. ${ }^{8}$

\section{Evaluation of FLU-TELSParticle Size and Polydispersity Index}

Dynamic Light Scattering (DLS), (Nanotrac Particle Size Analyzer) was used to determine the particle size and polydispersity index (PDI) of FLU-TELS.

\section{Entrapment Efficiency}

Entrapment efficiency for all the formulations was determined by using ultracentrifugation method. About $2 \mathrm{ml}$ of the formulations were subjected to

\begin{tabular}{|c|c|c|c|c|c|c|c|c|c|c|c|c|}
\hline Ingredients & F1 & F2 & F3 & F4 & F5 & F6 & F7 & F8 & F9 & F10 & F11 & F12 \\
\hline Drug (mg) & 50 & 50 & 50 & 50 & 50 & 50 & 50 & 50 & 50 & 50 & 50 & 50 \\
\hline $\begin{array}{c}\text { Lipid/ } \\
\text { Surfactant Ratio }\end{array}$ & $95: 05$ & $95: 05$ & $95: 05$ & $85: 15$ & $85: 15$ & $85: 15$ & $95: 05$ & $95: 05$ & $95: 05$ & $85: 15$ & $85: 15$ & $85: 15$ \\
\hline Lipid (mg) & 950 & 950 & 950 & 850 & 850 & 850 & 950 & 950 & 950 & 850 & 850 & 850 \\
\hline Span $80(\mathrm{mg})$ & 50 & 50 & 50 & 150 & 150 & 150 & -- & -- & -- & -- & -- & -- \\
\hline Tween 80 (mg) & -- & -- & -- & -- & -- & -- & 50 & 50 & 50 & 150 & 150 & 150 \\
\hline Ethanol (ml) & 40 & 30 & 20 & 40 & 30 & 20 & 40 & 30 & 20 & 40 & 30 & 20 \\
\hline $\begin{array}{l}\text { Phosphate Buffer } \\
\text { Saline (ml) }\end{array}$ & 60 & 70 & 80 & 60 & 70 & 80 & 60 & 70 & 80 & 60 & 70 & 80 \\
\hline
\end{tabular}


ultracentrifugation to separate the unentrapped drug from the dispersion by using an Ultracentrifuge (Sorval MX 150, Thermo Scientific Ultracentrifuge, US) at 15,000 rpm for $60 \mathrm{~min}$ at a temperature of $4^{\circ} \mathrm{C}$. The supernatant containing free drug and pellets of transethosomes were obtained. Transethosomal pellets were washed with PBS of $\mathrm{pH} 7.4$ for removal of the unentrapped drug by centrifugation. The combined supernatant was diluted with PBS of $\mathrm{pH} 7.4$ and quantified spectrophotometrically at $247.0 \mathrm{~nm}$ by UV spectrophotometer (Shimadzu -1800, Japan). ${ }^{?}$

\section{Entrapment Efficiency $=(\mathrm{A} 1-\mathrm{A} 2) * 100 / \mathrm{A} 1$}

A1- Amount of flurbiprofen added initially, A2Amount of flurbiprofen determined in the filtrate by spectrophotometry, A1-A2 -Represents the amount of flurbiprofen entrapped in the formulation.

\section{Deformability Index}

The FLU-TELS were allowed to extrude for $5 \mathrm{~min}$ through a $50 \mathrm{~nm}$ pore size sandwich nylon filter by applying a constant pressure of $0.5 \mathrm{MPa} .{ }^{10}$ The following equation was used for calculating the deformability index of the vesicles:

$\mathrm{DI}=\mathrm{J}\left(\frac{\mathrm{r}_{\mathrm{v}}}{\mathrm{r}}\right)^{2}$

D.I. $=$ Deformability Index, $\mathrm{J}=$ rate of penetration through a membrane filter (the weight of suspension extruded in $5 \mathrm{~min}$ ), $\mathrm{r}_{\mathrm{v}}=$ vesicle size (after extrusion), $\mathrm{r}_{\mathrm{p}}$ $=$ pore size of membrane.

\section{In vitro Drug Release}

The in-vitro drug release study was conducted in PBS of pH 7.4 using Franz diffusion cells (PermeGear, Inc., PA, USA) with an effective surface area of 1.77 $\mathrm{cm}^{2}$. Dialysis membrane (HiMedia Laboratories Pvt Ltd) having a molecular weight cut off 12,000-14,000 Daltons was used as the diffusion barrier between the donor and receptor compartments. The receptor compartment was filled with $12 \mathrm{ml}$ of PBS of $\mathrm{pH} 7.4$ and maintained at a temperature of $37 \pm 0.2^{\circ} \mathrm{C}$ with a stirring speed of $100 \pm 4 \mathrm{rpm}$. The membrane was affixed between the donor and receptor compartments and $1 \mathrm{ml}$ of the FLU-TELS equivalent to $5 \mathrm{mg}$ of the drug was placed in the donor compartment over the dialysis membrane. Aliquots were withdrawn at 1, 2, $3,4,6,8,10,12$ and $24 \mathrm{~h}$ followed by replacing the fresh buffer medium in the receptor compartment to maintain sink conditions. The samples were analysed at $247.0 \mathrm{~nm}$ by UV spectrophotometer after dilution with PBS of $\mathrm{pH} 7.4$ to quantify the cumulative drug release through FLU-TELS. ${ }^{11}$

\section{Zeta Potential Analysis}

The zeta potential of the optimised FLU-TELS was determined with Malvern Zetasizer at a fixed angle of $90^{\circ}$ at $25^{\circ} \mathrm{C}$ using Millipore water as a dispersing medium. ${ }^{12}$

\section{Morphology Studies \\ Electron Microscopy}

Twenty microliters of the optimized formulation was pipetted out with a micropipette and diluted up to $1 \mathrm{ml}$. A small drop of this solution containing transethosomal vesicles was placed on a glass slide, covered with a cover slip and observed under Trinocular electron microscope.

\section{Scanning Electron Microscopy (SEM)}

The dried FLU-TELS of the optimized formulation were fixed on a SEM-stub. This was followed by coating of the sample with a thin layer of gold under vacuum by Sputter Coater JFC-1600 (JEOL, Japan). The samples were run and observed with the help of JSM-6360LV Scanning Electron Microscope (JEOL, Japan) at an accelerated voltage of $10 \mathrm{kV} \cdot{ }^{13}$

\section{Transmission Electron Microscopy (TEM)}

The optimized formulation was sonicated and placed on a copper grid. Images were captured with the help of Digital Micrograph and Soft imaging software for analysis and particle sizing.

\section{Stability Studies}

Short term stability studies were conducted according to ICH GCP guidelines to establish the stability of the optimised TELs. The formulation was stored in glass vials in a humidity control oven at $25 \pm 2{ }^{\circ} \mathrm{C} / 65 \pm 5 \% \mathrm{RH}$ and refrigerated at $4 \pm 2^{\circ} \mathrm{C} / 65 \pm 5 \% \mathrm{RH}$. The sample was withdrawn at intervals of 30,60 and 90 days for analysis of particle size and $\%$ entrapment efficiency. ${ }^{14}$

\section{Evaluation of FLU TELs Gel Determination of pH}

The $\mathrm{pH}$ of FLU-TELS gel formulation was determined by adding $0.5 \mathrm{~g}$ of the gel in $20 \mathrm{ml}$ of double distilled water followed by stirring for 30 min using a magnetic stirrer. The $\mathrm{pH}$ was measured by immersing the probe of the $\mathrm{pH}$ meter into the dispersed gel, the $\mathrm{pH}$ was determined by reading on the digital display. ${ }^{8}$

\section{Drug Content}

The drug content of the gel formulation was determined by taking $1 \mathrm{~g}$ of the gel in $100 \mathrm{ml}$ of clean volumetric flask followed by making up the volume with methanol. The solution was stirred for $2 \mathrm{~h}$ using a magnetic stirrer and allowed to stand for $24 \mathrm{~h}$. Subsequently, the solution 
was filtered and analysed by UV spectrophotometer at $247 \mathrm{~nm}^{15}$

\section{Ex vivo Permeation Study}

Porcine ear pinna skin was used for carrying out the experiment. The skin was purchased from local slaughter house and prepared according to the method described by Garg et al. This study was carried out by affixing porcine ear pinna skin between the donor and receptor compartment of the Franz Diffusion cells. $1 \mathrm{~g}$ of the FLU-TELS gel corresponding to $5 \mathrm{mg}$ of the drug was placed in the donor compartment. The procedure followed for this experiment is similar to the one described for in-vitro drug release study. Aliquots were collected and analysed by UV spectrophotometer at $\lambda_{\max } 247 \mathrm{~nm}^{6}{ }^{6}$

$\mathrm{J} \max =\frac{\text { Amount of permeated drug }}{\text { Time X effective area of skin }}$

\section{Skin Deposition Study}

The porcine ear pinna skin mounted on Franz diffusion cell was carefully removed after $24 \mathrm{hr}$ and washed with PBS of $\mathrm{pH} 7.4$ for 5 times to remove the excess

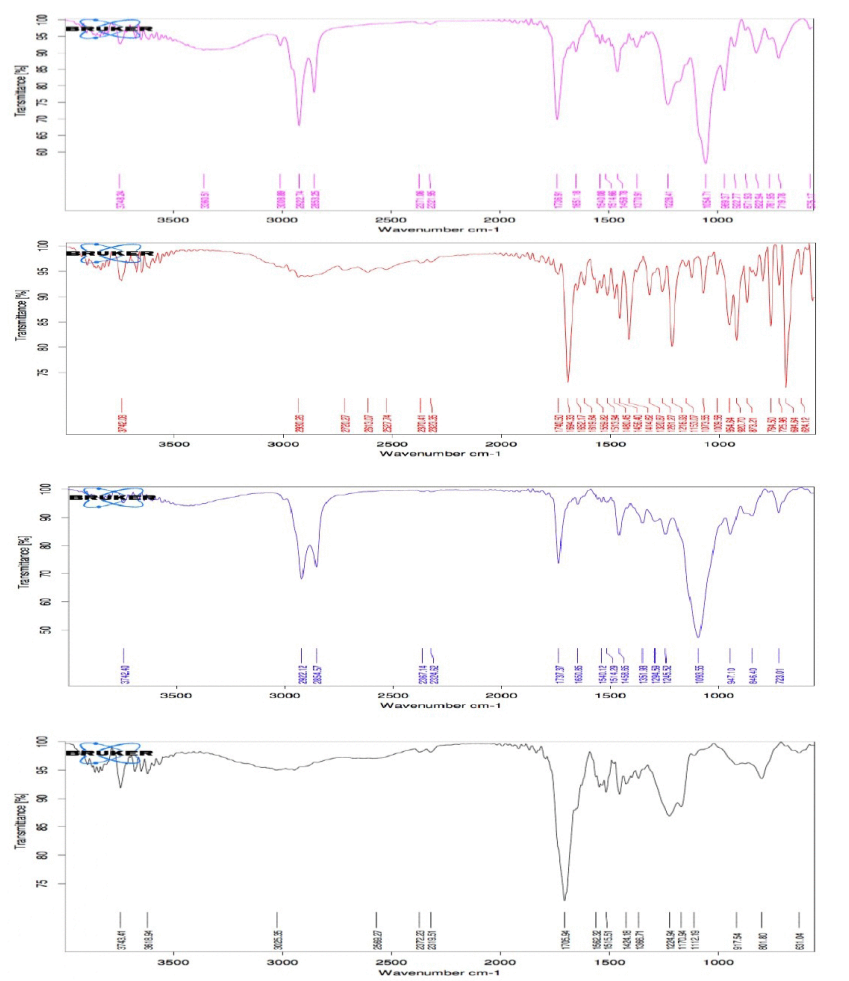

1. FTIR Spectrum of the Drug

2. FTIR Spectrum of Physical Mixture of Drug + Lipid + Span 80

3. FTIR Spectrum of Physical Mixture of Drug + Lipid + Tween 80

4. FTIR Spectrum of Physical Mixture of Drug + Carbapol 940

Figure 1: FTIR spectrum of the drug and the different polymers. drug from the skin. Tissue suspension was prepared by homogenising the cut skin pieces with methanol followed by centrifugation. The supernatant was filtered with the help of $0.45 \mu \mathrm{m}$ syringe filter and further diluted for analysis by UV spectrophotometer at 247 $\mathrm{nm} .{ }^{16}$

\section{Stability Studies}

The FLU-TELS gel formulation was stored in glass vials in a humidity control oven at $25 \pm 2^{\circ} \mathrm{C} / 65 \pm 5 \%$ $\mathrm{RH}$ and refrigerated at $4 \pm 2^{\circ} \mathrm{C} / 65 \pm 5 \% \mathrm{RH}$. The sample was withdrawn at intervals of 30, 60 and 90 days for visual analysis and drug content. ${ }^{14}$

\section{RESULTS AND DISCUSSION}

The Transethosomal formulations (F-1 to F-12) were successfully prepared by varying the ratio of $\mathrm{EA}$ and SPC and using different percentage of ethanol. Subsequently, all the formulations were subjected to various physicochemical evaluations. The formulation which showed the least particle size, highest deformability index, sufficient entrapment efficiency and best in-vitro drug release profile was optimized for further studies. The optimized formulation was dispersed in a gelling agent and further evaluated for $\mathrm{pH}$, drug content, ex vivo studies and skin deposition.

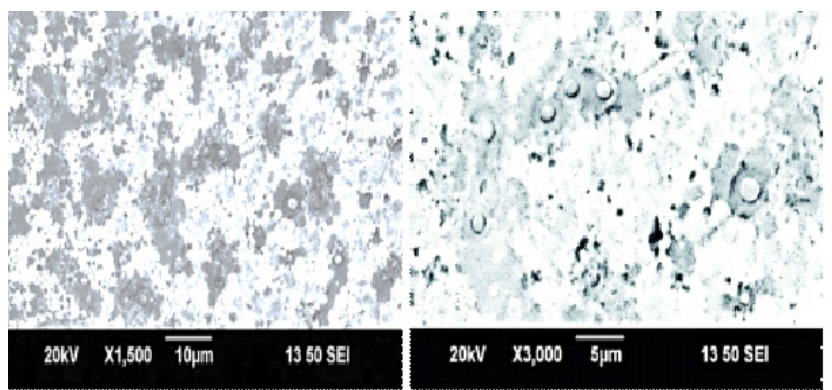

2(a). SEM image of FLU-TELS (F10)
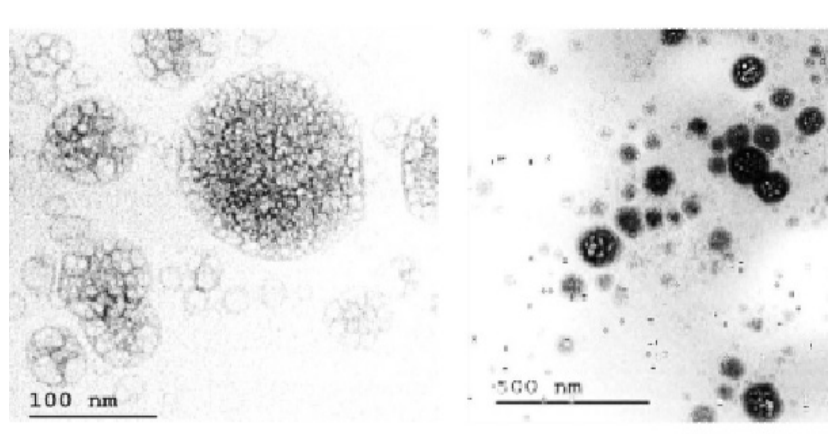

2(b). TEM Images of FLU-TELS (F10)

Figure 2: SEM and TEM images of the FLU-TELS of the optimized formulation (F10). 


\section{Evaluation of FLU TELS FTIR}

Characteristic IR peaks were detected at $1697.27 \mathrm{~cm}$, ( $\mathrm{C}=\mathrm{O}$ stretch), $1216.25 \mathrm{~cm}$ (aromatic C-F stretch), $-\mathrm{CH} 3$ stretch $(1378.80 \mathrm{~cm}$ band) and $957.46 \mathrm{~cm}(\mathrm{OH}$ out of plane deformation band) in the spectrum of pure Flurbiprofen. These peaks were also found in combination spectrums with some or no difference which depicts compatibility of the drug with excipients (Figure 1).

\section{SEM and TEM}

The vesicles appeared as smooth spherical shaped discrete particles. Whereas, in TEM it was observed that the vesicles were irregular spherical shaped in the nanoscale range of 500-100 $\mathrm{nm}$. As shown in (Figure 2a and $2 b)$.

\section{Mean Particle Size Determination}

The mean particle size for formulations containing Span 80 (F-1 to F-6) as the EA ranged from $152.06 \pm 5.10$ to $215.2 \pm 0.53 \mathrm{~nm}$, however the mean particle size for formulations containing Tween 80 as EA (F-7 to F-12) ranged between $107.7 \pm 0.43$ to $186.2 \pm 1.06 \mathrm{~nm}$. The particle size decreased with increase in EA concentration in case of formulations containing Tween 80; however, a reverse correlation was observed when Span 80 was used as the EA. This can be attributed to the solubilizing property of Tween 80 which leads to decrease in particle size with increasing concentration. ${ }^{17}$

An inverse relationship was observed between the mean particle size and increase in ethanol concentration (up to $40 \%$ ) in all formulations. Formulations (F-1, F-4, F-7 and F-10) containing 40\% ethanol content showed less particle size than those containing 30\% (F-2, F-5, F-8 and F-11) and 20\% ethanol (F-3, F-6, F-9 and F-12). Thus, it can be concluded that the particle size decreases with increase in ethanol concentration and vice versa (Table 2). According to previously reported studies, increase in ethanol concentration decreases size of the particles due to interpenetration of the ethanol hydrocarbon chain leading to reduce in size of the particles because of decrease in the thickness of the vesicular membrane. ${ }^{18-20}$

\section{Polydispersity Index}

Polydispersity index value of all formulations (F-1 to F-12) varied in the range of $0.223 \pm 0.011$ to $0.464 \pm 0.18$ which indicated mono-dispersed particle distribution (Table 2).

\section{Entrapment Efficiency}

Formulation F-1 containing Span 80 as the EA and $40 \%$ ethanol showed the highest entrapment efficiency of $76.0 \pm 0.53$. Moreover, the entrapment efficiency decreased in formulations containing Span 80 (F-1 to F-6) with decrease in EA, however a reverse trend was observed for formulations containing Tween 80 (Table 2). This is because Span 80 having a lower HLB value of 4.3 can entrap more amount of hydrophobic Flurbiprofen in contrast to Tween 80 having a HLB value of 15. Ethanol had a positive effect on the entrapment of all formulations irrespective of surfactant type which may be attributed to the solubilization of Flurbiprofen by ethanol. ${ }^{21,22}$

\section{Deformability Index}

The deformability index was observed for all the formulation batches. As shown in (Figure 3). The deformability index ranged from $0.55 \pm 0.17$ to

\begin{tabular}{|c|c|c|c|}
\hline \multicolumn{5}{|c|}{ Table 2: Evaluation of Flurbiprofen Loaded } \\
Transethosomal Suspension. \\
\hline $\begin{array}{c}\text { Formulation } \\
\text { Code }\end{array}$ & $\begin{array}{c}\text { Particle } \\
\text { Size (nm) }\end{array}$ & $\begin{array}{c}\text { Polydispersity } \\
\text { Index (Mw) }\end{array}$ & $\begin{array}{c}\text { \% Entrapment } \\
\text { Efficiency }\end{array}$ \\
\hline F-1 & $152.06 \pm 0.81$ & $0.417 \pm 0.23$ & $76.0 \pm 0.53$ \\
\hline F-2 & $171.63 \pm 0.47$ & $0.246 \pm 0.07$ & $73.30 \pm 0.90$ \\
\hline F-3 & $197.13 \pm 0.85$ & $0.313 \pm 0.13$ & $67.19 \pm 0.24$ \\
\hline F-4 & $184.00 \pm 0.71$ & $0.252 \pm 0.12$ & $63.07 \pm 0.71$ \\
\hline F-5 & $195.30 \pm 0.91$ & $0.464 \pm 0.18$ & $59.26 \pm 0.20$ \\
\hline F-6 & $215.20 \pm 0.53$ & $0.260 \pm 0.55$ & $54.46 \pm 0.38$ \\
\hline F-7 & $134.86 \pm 0.16$ & $0.266 \pm 0.11$ & $52.27 \pm 0.14$ \\
\hline F-8 & $142.06 \pm 0.61$ & $0.306 \pm 0.21$ & $50.46 \pm 0.49$ \\
\hline F-9 & $186.20 \pm 0.66$ & $0.375 \pm 0.74$ & $48.57 \pm 0.38$ \\
\hline F-10 & $107.70 \pm 0.43$ & $0.271 \pm 0.11$ & $71.90 \pm 0.29$ \\
\hline F-11 & $114.80 \pm 0.57$ & $0.223 \pm 0.11$ & $68.49 \pm 0.17$ \\
\hline F-12 & $124.30 \pm 0.43$ & $0.259 \pm 0.07$ & $64.53 \pm 0.51$ \\
\hline
\end{tabular}

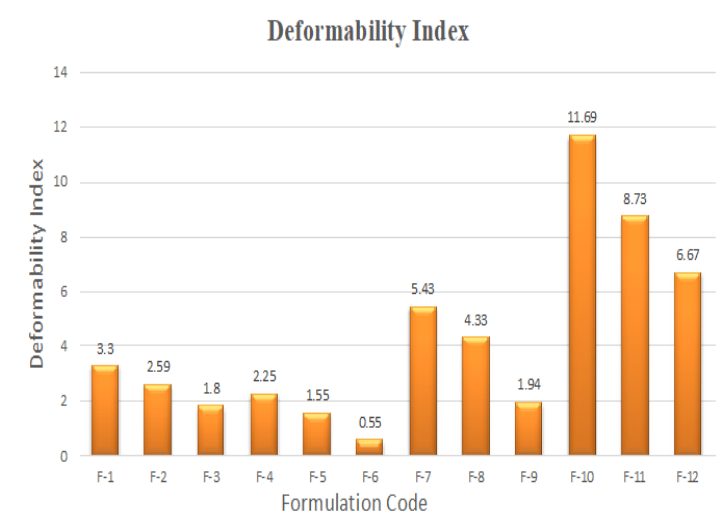

Figure 3: The Deformability Index of the formulation batches. 
$11.69 \pm 0.82$ with highest elasticity index observed for F-10 (optimized batch). Transethosomes containing Tween 80 had higher deformability index than formulations containing Span 80 because Tween 80 provides highly malleable characteristics to the vesicles and has less bulky chains than Span $80 .{ }^{23}$ In addition, optimum ethanol concentration $(40 \%)$ provided elastic properties to the vesicles which enhanced the passage of vesicles through the pores of the nylon filter on application of $0.5 \mathrm{MPa}$ pressure. ${ }^{24}$ Thus, F-10 containing the highest ethanol percentage and Tween 80 concentration showed the maximum deformability in comparison to other formulations.

\section{In-vitro Drug Release}

FLU-TELS formulations (F-1 to F-12) was found to be in the range of $41.25 \pm 0.60 \%$ to $69.18 \pm 0.07 \%$ with F-3 showing the least amount of drug released and F-10 showing the maximum amount of drug released after $24 \mathrm{~h}$. The release was found to be affected by EA type, ratio and ethanol concentration. All formulations containing $40 \%$ ethanol showed better release profile. F-10 containing the highest amount of Tween 80 and highest percentage of ethanol $(40 \%)$ showed the best release profile $(69.18 \pm 0.07)$ in comparison to other formulations. This is because Tween 80 provides elastic characters to the vesicles by destabilizing the lipid bilayers without impacting the integrity of the vesicles. SPC also enhances the release of vesicles. Lastly, ethanol acts in a synergic manner to enhance the elasticity and decreases the particle size of the vesicles thereby leading to ease in penetration of vesicles through the dialysis membrane. Furthermore, a burst release was observed in the initial $6 \mathrm{hr}$ due to the surface-adsorbed drug followed by sustained release in the next $24 \mathrm{hr}$. The figures for graphical comparison of the percentage cumulative drug release with Span 80 as EA (F-1 to F-6) and percentage cumulative drug release with Tween 80 as EA (F-7 to F-12) are depicted in Figure 4a and Figure $4 \mathrm{~b}$ respectively. Formulation F-10 was selected for further studies as the optimized formulation because it had the least particle size, highest deformability, acceptable entrapment efficiency and best drug release profile.

\section{Zeta Potential}

The zeta potential of the optimized formulation F-10 was found to be $-30.09 \pm 0.46 \mathrm{mV}$ which indicates stable formulation. The optimized FLU-TELS was dispersed in 2\% Carbopol 940. The optimized gel formulation was yellowish white in colour which showed good consistency on visual observation.

\section{Morphological Characterization}

When observed under an electron microscope, the FLU-TELS of the F-10 formulation appeared as nearly spherical bilayered vesicles. On SEM analysis, the vesicles appeared as smooth spherical shaped discrete particles. However, the vesicles were irregular spherical shaped in the nano-scale range of $500-100 \mathrm{~nm}$ when analysed with the help of Transmission Electron Microscope.

\section{Selection of Optimized Formulation}

Based on the evaluation parameters F-10 was selected as the optimized formulation because it had the least particle size, highest deformability, acceptable entrapment efficiency and best drug release profile. Formulation F10 was taken for incorporating into the gel for topical preparation.

\section{Evaluation of FLU TELs Gel}

Optimized F-10 FLU-TELS formulation was used to prepare transethosomal Gel and the gel was evaluated for content determination, $\mathrm{pH}$ study, viscosity, spreadibility, ex vivo permeation studies and skin deposition study

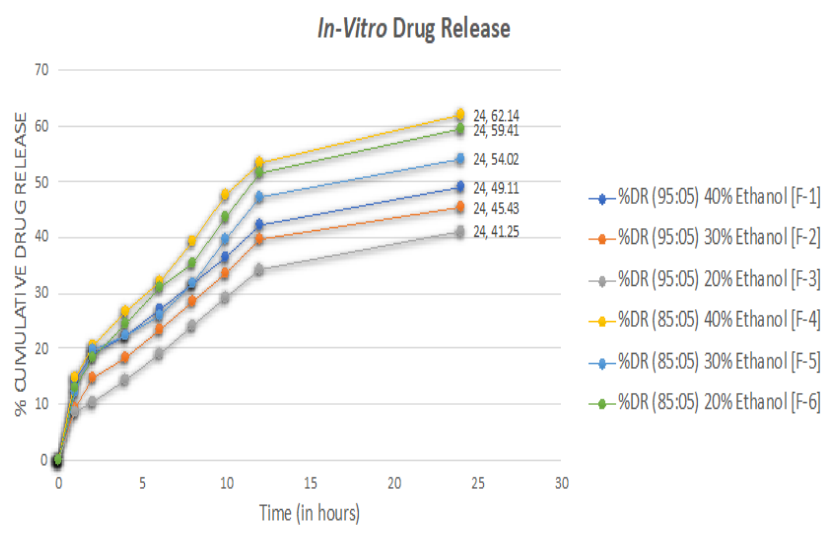

Figure 4a: Dissolution Profile of Formulation batch F-1 to F-6 in PBS pH 7.4.

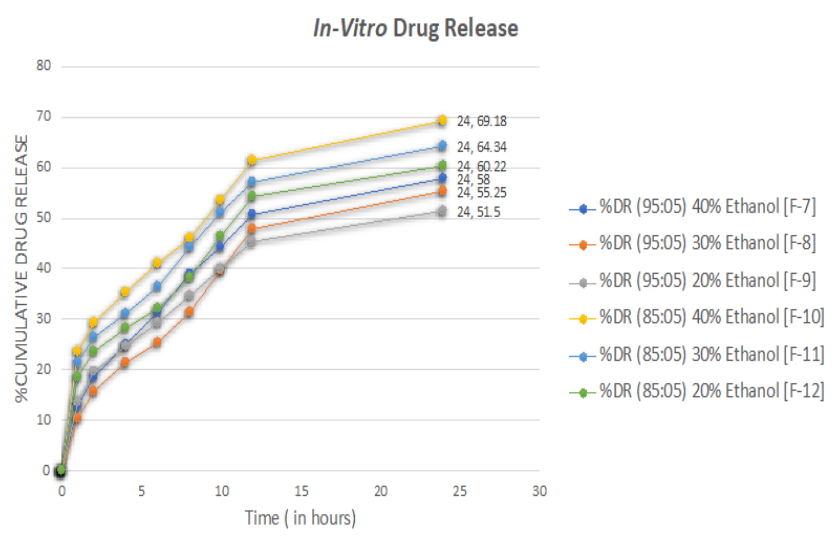

Figure 4b: Dissolution Profile of Formulation batch F-7 to F-12 in PBS pH 7.4. 
which is shown in Table 3. The drug content for the optimized transethosomal gel was found to be 98.23 \pm 0.87. The $\mathrm{pH}$ of the optimized formulation was indicating skin-compatibility and viscosity was depicting Non-Newtonian plastic flow without thixotropic characteristics. The spreadibility shows that the gel is of semi-fluid nature.

\section{EX-vivo permeation Studies}

For the ex vivo Permeation Studies comparison between marketed gel cream, Hydroethanolic solution and F-10 TELs gel, Marketed gel, Hydroethanolic solution at the end of $24 \mathrm{~h}$ was found to be $26.06 \pm 0.83 \mu \mathrm{g}$

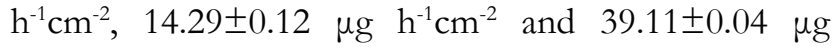
$\mathrm{h}^{-1} \mathrm{~cm}^{-2}$ respectively which demonstrates that TELs gel have better ex vivo permeation than the other two because of the integrating effect of phospholipid and EA (Tween 80) which provide tactile characteristics to the vesicles easing penetration. Moreover, ethanol as a permeation enhancer eases increasing inter and intracellular permeability of vesicles across the Stratum corneum layer.

\section{Skin Deposition Studies}

The deposition of flurbiprofen from TELs gel on porcine pinna skin (Figure 5) was found to be $19.45 \pm 0.76 \%$ which was 2.16 folds higher than marketed formulation $(8.97 \pm 0.41 \%)$ and 3.76 folds

\begin{tabular}{|c|c|}
\hline Evaluation Parameters & Results \\
\hline Drug Content & $98.23 \pm 0.87 \%$ \\
\hline $\mathrm{pH}$ & $6.61 \pm 0.18$ \\
\hline Viscosity & $492.76 \pm 0.15 \mathrm{cps}$ \\
\hline Spreadibility & $2.03 \pm 0.15$ \\
\hline Ex vivo permeation studies & $26.06 \pm 0.83 \mu \mathrm{g} \mathrm{h}-1 \mathrm{~cm}-2$ \\
\hline
\end{tabular}

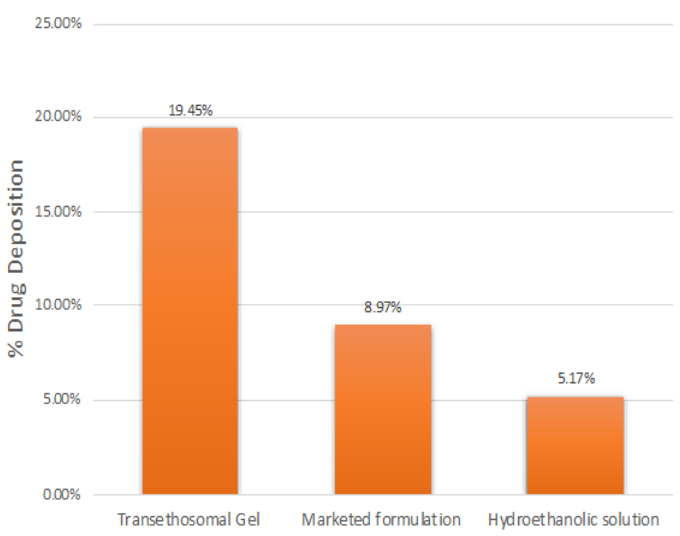

Figure 5: The \% Drug Deposition studies of Transethosomal gel vs Marketed Formulation vs Hydroethanolic Solution. higher than Hydroethanolic solution (5.17 $\pm 0.33 \%$ ). Thus, it can be concluded that the formulated TELs gel has better skin deposition as it contains EA, SPC and ethanol which synergically aid in skin permeation and deposition of drug.

\section{Stability study}

The stability study was conducted on both optimized FLU-TELS and FLU-TELS gel formulation. In case of FLU-TELS, it was observed that there was no any significant change in particle size and entrapment efficiency, thus the formulation was found stable in both conditions of room temperature and refrigerator. In case of FLU-TELS gel there was no any significant change in appearance and drug content was observed, thus the formulation was found stable at room temperature.

\section{CONCLUSION}

In the present study, it was demonstrated that transethosomes consisting of the highest percentage of ethanol (up to $40 \%$ ) and maximum concentration of Tween 80 as the EA had the lowest particle size, highest elasticity and the best drug release profile than other formulations containing lower ethanol percentage or Span 80 as an EA. Besides, the optimised formulation dispersed in Carbopol 940 showed better skin deposition and ex-vivo permeation than the marketed formulation and Hydroethanolic solution. Thus, from the results it can be concluded that FLU-TELS gel containing the highest percentage of ethanol and highest concentration of Tween 80 could be a potential carrier for the dermal delivery of the hydrophobic drug, Flurbiprofen.

\section{ACKNOWLEDGEMENT}

The authors would like to acknowledge the Principal KLE College of Pharmacy, Belagavi and Dr. Prabhakar Kore Basic Science Research Centre, Belagavi for providing laboratory facilities. The authors are thankful to AICTE MODROB for providing the probe sonicator facility. The authors would also like to thank STIC, Cochin University, India and Diya Labs, Mumbai, India for SEM and TEM analysis of the samples.

\section{CONFLICT OF INTEREST}

The authors declare no conflict of interest.

\section{ABBREVIATIONS}

FLU TELS: Flurbiprofen loaded transethosomal suspension; FLU TELs Gel: Flurbiprofen loaded 
transethosomal gel; TELs Gel: Transethosomal gel; SPC: Soyaphostidylcholine; EA: Edge Activator; PBS: Phosphate Buffer Solution.

\section{REFERENCES}

1. Anderson B, Conradi R. Predictive relationships in the water solubility of salts of a nonsteroidalanti-inflammatory drug. J Pharma Sci. 1985;74(8):815-20.

2. Richy F, Rabenda V, Mawet A, Reginster J. Flurbiprofen in the symptomatic management of rheumatoid arthritis: A valuable alternative. Int J Clin Pract. 2007;61(8):1396-406.

3. Rannou F, Pelletier J, Martel-Pelletier J. Efficacy and safety of topical NSAIDs in the management of osteoarthritis: Evidence from real-life setting trials and surveys. Semin Arthritis Rheu. 2016;45(4):S18-21.

4. Rastogi V, Yadav P. Transdermal drug delivery system: An overview. Asian J Pharm Sci. 2012;6(3):161-70.

5. Gupta A, Aggarwal G, Singla S, Arora R. Transfersomes: A novel vesicular carrier for enhanced transdermal delivery of sertraline: Development, characterization and performance evaluation. Sci Pharma. 2012;80(4):106180.

6. Charoo N, Anwer A, Kohli K, Pillai K, Rahman Z. Transdermal delivery of flurbiprofen: permeation enhancement, design, pharmacokinetic and pharmacodynamic studies in albino rats. Pharm Dev Technol. 2005;10(3):34351.

7. Albash R, Abdelbary A, Refai H, El-Nabarawi M. Use of Transethosomes for enhancing the transdermal delivery of Olmesartanmedoxomil: in vitro, ex vivo and in vivo Evaluation. Int J Nanomedicine. 2019;14:1953-68.

8. Abdulbaqi IM, Darwis Y, Abou AR, Khan NA. Transethosomal gels as carriers for the transdermal delivery of colchicine: Statistical optimization, characterization and ex vivo evaluation. Drug Des Devel Ther. 2018;12:795813.

9. Maurya S, Prajapati S, Gupta A, Saxena G, Dhakar R. Formulation development and evaluation of ethosome of stavudine. Indian $\mathrm{J}$ Pharm Educ. 2010;44(1):102-8.

10. Song C, Balakrishnan P, Shim C, Chung S, Chong S, Kim D. A novel vesicular carrier, transethosome, for enhanced skin delivery of voriconazole: Characterization and in vitro / in vivo evaluation. Colloid Surface B. 2012;92:299-304.
11. Shaji J, Garude S. Transethosomes and ethosomes for enhanced transdermal delivery of ketorolac tromethamine: A comparative assessment. Int $\mathrm{J}$ Curr Pharm Res. 2014;6(4):88-93

12. Honary S, Zahir F. Effect of zeta potential on the properties of nano-drug delivery systems-a review (Part 1). Trop J Pharm Res. 2013;12(2):255-64.

13. Haloi A. Application of electron microscope technique in anthropological research: A review. The Anthropologist. 2015;21(1-2):331-40.

14. ICH Topic Q1A (R2) Stability testing of new drug substance and product. CPMP/ICH/2736/99. 2003. https://www.ema.europa.eu/en/documents/ scientific-guideline/ich-q-1-r2-stability-testing-new-drug-substancesproducts-step-5_en.pdf

15. Mbah C, Builders P, Nzekwe I, Kunle O, Adikwu M, Attama A. Formulation and in vitro evaluation of $\mathrm{pH}$-responsive ethosomes for vaginal delivery of metronidazole. J Drug Deliv Sci Tec. 2014;24(6):565-71

16. Raza K, Singh B, Mahajan A, Negi P, Bhatia A, Katare OP. Design and evaluation of flexible membrane vesicles (FMVs) for enhanced topical delivery of capsaicin. J Drug Target. 2011;19(4):293-302.

17. Shen S, Liu S, Zhang Y, Du M, Liang A, Song L, et al. Compound antimalarial ethosomal cataplasm: Preparation, evaluation and mechanism of penetration enhancement. Int J Nanomedicine. 2015;10:4239.

18. Ainbinder D, Touitou E. Testosterone Ethosomes for enhanced transdermal delivery. Drug Deliv. 2005;12(5):297-303.

19. Paolino D, Lucania G, Mardente D, Alhaique F, Fresta M. Ethosomes for skin delivery of ammonium glycyrrhizinate: In vitro percutaneous permeation through human skin and in vivo anti-inflammatory activity on human volunteers. J Control Release. 2005;106(1-2):99-110.

20. Magnusson B, Runn P, Karlsson K, Koskinen L. Terpenes and ethanol enhance the transdermal permeation of the tripeptidethyrotropin releasing hormone in human epidermis. Int J Pharm. 1997;157(1):113-21.

21. Bnyan R, Khan I, Ehtezazi T, Saleem I, Gordon S, O'Neill F, et al. Surfactant Effects on Lipid-Based Vesicles Properties. J Pharma Sci. 2018;107(5):123746.

22. Garg V, Singh H, Bhatia A, Raza K, Singh S, Singh B, et al. Systematic development of transethosomal gel system of piroxicam: Formulation optimization, in vitro evaluation and ex vivo assessment. AAPS Pharm Sci Tech. 2016;18(1):58-71.

23. Khan M, Pandit J, Sultana Y, Sultana S, Ali A, Aqil M, et al. Novel carbopolbased transfersomal gel of 5-fluorouracil for skin cancer treatment:in vitro characterization andin vivostudy. Drug Delivery. 2014;22(6):795-802.

24. Van den Bergh B, Wertz $P$, Junginger $H$, Bouwstra J. Elasticity of vesicles assessed by electron spin resonance, electron microscopy and extrusion measurements. Int J. Pharma. 2001;217(1-2):13-24.

\section{SUMMARY}

- TELS suspensions were formulated by thin film hydration method using different ratios of SPC:EA with varying percentage of ethanol.

- It was found that EA type, ratio and ethanol concentration had an impact on particle size, deformability, entrapment efficiency and in-vitro drug release.

- F-10 containing the highest concentration of Tween 80 and maximum percentage of ethanol (up to $40 \%$ ) showed the least particle size, acceptable entrapment efficiency, maximum deformability and the highest in-vitro drug release.

- The optimised F-10 formulation was incorporated into the gel base (2\% Carbopol). The $\mathrm{pH}$ was compatible with the skin $\mathrm{pH}$, spreadability depicted the nature of the gel to be semi-fluid and viscosity studies indicated non-Newtonian plastic flow with no thixotropic characteristics.

- On comparison with the marketed cream gel and hydroethanolic solution (30\%), TELs gel showed the best ex-vivo profile and the maximum skin deposition.

- In a nutshell, flurbiprofen loaded transethosomal gel can be formulated for the treatment of arthritis, as the gel has good ex-vivo permeation, skin-deposition and reduced dose. 


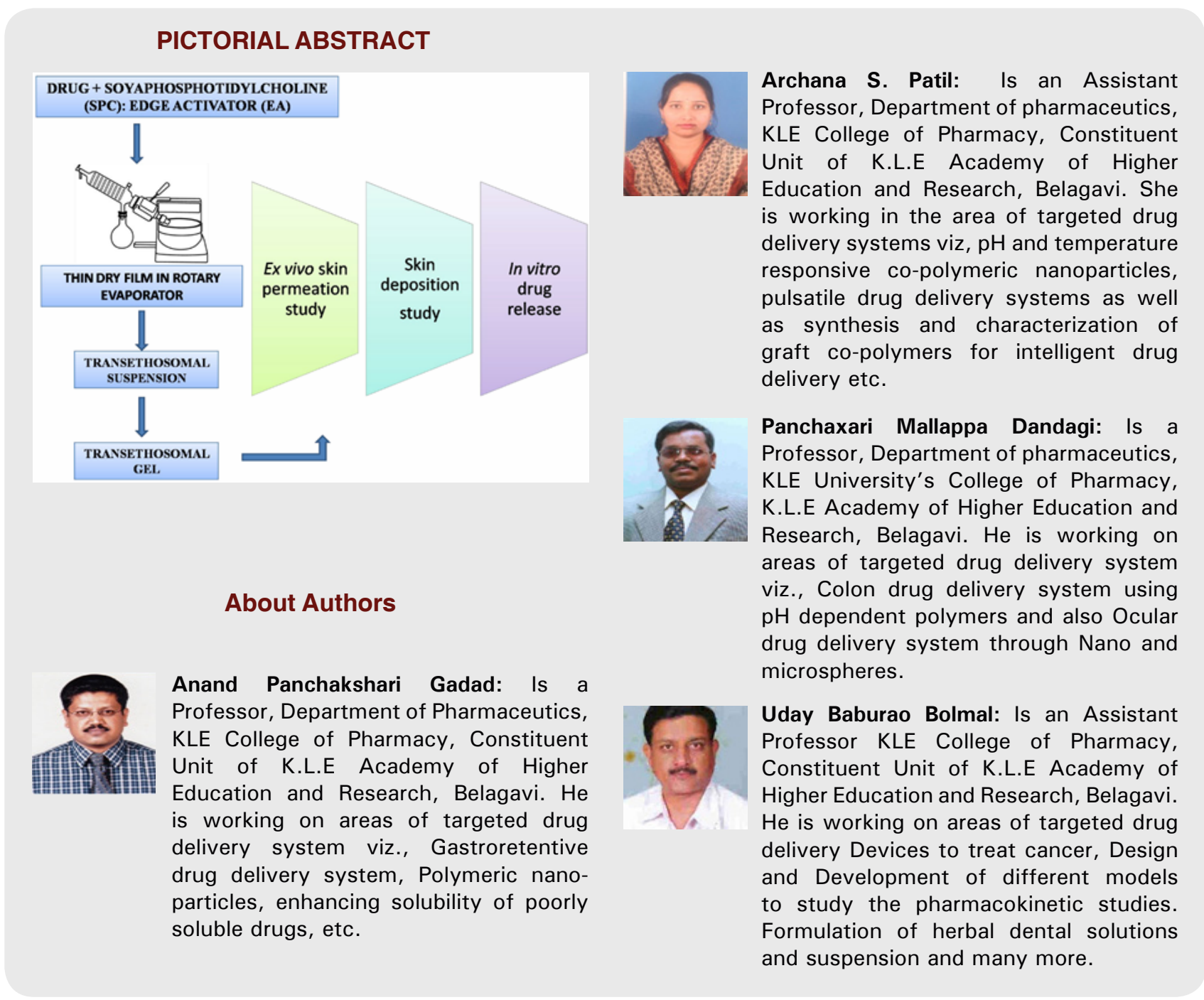

Cite this article: Gadad AP, Patil AS, Singh Y, Dandagi PM, Bolmal UB, Basu A. Development and Evaluation of Flurbiprofen Loaded Transethosomes to Improve Transdermal Delivery. Indian J of Pharmaceutical Education and Research. 2020;54(4):954-62. 